\title{
Evaluation of ICTs access, use and preferences for livelihood resilience: results from a survey of Malaysian fisher folks
}

\begin{abstract}
Purpose: This paper examined access, use and preferences of Information Communication Technologies (ICTs) for weather and flood risk communication towards livelihood resilience (LR) of agricultural communities. Methodology: Cross-sectional data were randomly collected from 362 fishers in east-coast Malaysia and analysed using descriptive statistics. Findings: Communication ICTs accessed are radio, television, mobile phone and social media, while fishing-based ICTs are sonar system, GPRS, echo sounder and wireless. Majority of the fisher folks uses mobile phones and social media for both weather, flood risk communication and advisory services. Preferred ICTs for advisory services are mobile phones, followed by television, while for weather and flood risks, television and social media are the most preferred. Practical Implication: Increased innovative ICTs use, especially the preferred ICTs identified can prove more effective and helpful in achieving governments' and regional priorities of creating more flood awareness and inciting flood risks perception, hence adaptation action for LR. Theoretical Implication: This research highlights the important role ICTs plays in building LR and the relevance of using preferred communication platforms for effective communication. Originality: This paper contributes to the scarce literature on the relevance of the use of ICTs in building LR within agricultural communities while extending grassroots' contribution towards achieving LR through expressed preferences of communication platforms.
\end{abstract}

Keyword: Livelihood resilience; ICTs use; Flood risks communication; Adaptation; Preferences; Fisher folks 